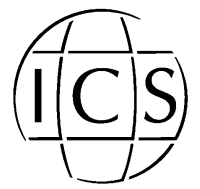

www.ics-elsevier.com

\title{
Human influenza surveillance in areas with animal flu epidemics and China visitors in Taiwan
}

\author{
Yie-Jen Liao $^{\mathrm{a}}$, Ching-Ping Tsai ${ }^{\mathrm{b}}$, Ming-Chu Cheng ${ }^{\mathrm{c}}$, \\ Chuan-Liang Kao ${ }^{\mathrm{a}}$, N. Cox ${ }^{\mathrm{d}}$, Chwan-Chuen King ${ }^{\mathrm{a}, *}$ \\ ${ }^{a}$ College of Public Health, Institute of Epidemiology, National Taiwan University, \\ 1 Jen-Ai Road Section 1, Taipei 100, Taiwan \\ ${ }^{\mathrm{b}}$ Animal Technology Institute, Taiwan \\ ${ }^{\mathrm{c}}$ Nat. Vet. Res. Inst., Taiwan \\ ${ }^{\mathrm{d}} \mathrm{CDC}$ in Atlanta, USA
}

\begin{abstract}
Background: This study investigates the changes in human flu viruses in areas where unique animal flu viruses or epidemics were isolated in Taiwan and Kinmen islet. Materials and methods: Sentinel physicians obtained throat swabs from patients presenting with flu-like illness and two-step RT-PCR, using five sets of primers for matrix (M) and HA2, to detect all the animal influenza viruses and then typing/subtyping for human flu viruses. Questionnaires included travel history, animal contacts and occupations. Results: One flu B and eight flu A H3N2 isolates were identified in the flu season of 2002-2003, including 1, 2, 2 and 3 H3N2 in Taoyuan, Yilan, Tainan and Kinmen, respectively. Amino acid sequences of HA of human isolates revealed that Pro (P) at position 227 among most of the Kinmen isolates (2/3) replaced Ser (S) in the Taiwanese isolates, including one mutant from Gln (Q) to His $(\mathrm{H})$ at position 156 of the HA gene for five out of eight H3N2 Taiwan isolates. Phylogenetic analysis demonstrated that all of the $\mathrm{H} 3 \mathrm{~N} 2$ viruses were of human origin (belonging to the lineage of A/Fujian/411/2002), with 80-90\% homology in HA, NA and M gene segments of A/Swine/PingTung/Taiwan/199.2/02 (H3N2) and 75-77\% homology in HA gene segment of A/Wild Bird/Taiwan/243/02(H3) and A/Mallard Duck/Taiwan/3.3/03 (H3). Conclusions: Residents in Kinmen islet frequently traveling from China need to monitor their flu A viruses that might be different from those obtained on the main Taiwan island. (C) 2004 Elsevier B.V. All rights reserved.
\end{abstract}

Keywords: Influenza; Surveillance; Taiwan

\section{Introduction}

Influenza A viruses circulate worldwide and cause annual epidemics of human respiratory illness [1,2]. Animals play an important role in reservoir and interspecies transmission of these viruses [3]. Three pandemics of human influenza A occurred in the 20th century, and recent bird flu epidemics of H5N1, H9N2 in Hong Kong and China, plus

\footnotetext{
* Corresponding author. Tel.: +886-2-2341-4371; fax: +886-2-2351-1955.
}

E-mail address: a1234567@ccms.ntu.edu.tw (C.-C. King). 
H7N7 in Holland in 2003 indicate that those novel flu A viruses were partially or entirely derived from avian flu viruses [4-6]. It is very likely that emerging and reemerging influenza A viruses with pandemic potential might currently be circulating in China. Taken together, these events reveal that the emergence of novel influenza A viruses still pose a pandemic threat.

Taiwan has high population density, many animal farms, habitats of migrating birds and tremendous numbers of travelers going to mainland China and Hong Kong. Therefore, an effective virological surveillance system of influenza A viruses is definitely required to reach public health goals. This study focused on the investigation of changes in human flu A viruses in those areas where animal flu epidemics occurred, unique animal flu viruses were isolated and the habitats of migration birds located in northern, central and southern Taiwan and the Kinmen islet were identified.

\section{Materials and methods}

\subsection{Study areas and collection of specimens}

Rural areas included important swine or domestic avian farms or migrating bird habitats or places with animal flu outbreaks located in different parts of Taiwan, including: (1) Yilan County, (2) Taoyuan County, (3) Changhwa County and (4) Tainan County located on the northeastern coast, northwestern, central and southern Taiwan, respectively. In addition, Kinmen islet, which is geographically very close to mainland China with many businessmen traveling back and forth between Kinmen and China, was also selected to pay more attention to the possible emergence of novel influenza viruses.

Sentinel physicians obtained throat swabs from children presenting with flu-like illness who had the following exposures: (1) living near the poultry farm, (2) having contact with swine or avian populations or (3) having a travel history to China/Hong Kong. These specimens were then transported to our laboratory by express service at $4{ }^{\circ} \mathrm{C}$.

\subsection{RNA extraction and RT-PCR}

Viral RNA was extracted from the culture supernatants of Madin-Darby Canine Kidney (MDCK) cells using a QIAamp viral RNA extraction kit (Cat.52906). Each of the viral gene segments was initially amplified by reverse transcriptase (RT), using the Uni12 primer (AGCAAAAGCAGG) (WHO Animal influenza manual). Subsequent PCR amplification of cDNA was accomplished using influenza A specific and subtype specific primer sets, matrix (M) gene (52-253, 244 bps) and HA gene (1144-R, 650 bps), which detected all the animal influenza viruses. We then used primer sets of flu B HA (55-127, 108 bps), human H1 (46-633, 650 bps) and human H3 (365-1072, 785 bps) for typing/ subtyping.

\subsection{Sequence analysis and phylogenetic analysis}

All sequence data were edited and translated by using the DNASTAR. Phylogenetic analysis was performed with maximum-parsimony algorithm and neighbor-joining method bootstrapping 1000 [7]. 


\subsection{Nucleotide sequence accession numbers}

The sequences of swine flu H3N2 virus (GenBank accession \#AY377927, \#AY377928) isolated from PingTung of Taiwan and the avian flu H3 viruses [A/Wild Bird/Taiwan/243/ 02(H3) and A/Mallard Duck/Taiwan/3.3/03 (H3)] isolated in Taiwan were kindly provided by Ching-Ping Tsai and Ming-Chu Cheng (unpublished data), respectively.

\section{Results}

\subsection{Isolation of influenza viruses in rural areas and Kinmen islet}

Among 65 samples collected from the flu season of 2002-2003, one flu B and eight human flu A H3N2 isolates were identified, including 1, 2, 2 and 3 H3N2 isolates obtained in Taoyuan, Yilan, Tainan and Kinmen islet, respectively. Epidemiological characteristics of those flu(+) cases were detected by isolation and RT-PCR (Table 1).

\subsection{Comparison of amino acid sequences of HA gene}

The amino acid sequences of the 2002-2003 human flu H3 HA genes were aligned and compared with Taiwan human flu strains in the past years. The results showed that: (1) amino acids, such as asparagine $(\mathrm{N})$ at position 144 (an antigenic site), glycine $(\mathrm{G})$ at position 186 and aspartic acid (D) at position 225, were all found in recent human flu Taiwan strains without changes; (2) proline (P) at position 227 among most of the Kinmen isolates $(2 / 3)$ was found to be replaced by serine $(\mathrm{S})$ in isolates obtained from main Taiwan island; and (3) one mutant at position 156 of HA, which is associated with a loss of hemadsorption activity and amino acid of glutamine (Q) found in past Taiwan Flu A strains since 1997, changed into histidine (H) for five out of eight isolates in 2003 (Table 2).

\subsection{Sequences of homology analysis}

Human flu H3N2 virus isolates in 2002-2003 showed 80-90\% homology with HA1 [414-924 (511 bp)], NA [562-939 (378 bp)] and M [89-276 (188 bp)] gene segments of

Table 1

Epidemiological information of human flu(+) cases detected by isolation in MDCK cells and two-step RT-PCR

\begin{tabular}{|c|c|c|c|c|c|c|c|}
\hline \multirow[t]{2}{*}{ ID \# } & \multirow{2}{*}{$\begin{array}{l}\text { Areas } \\
\text { in Taiwan }\end{array}$} & \multirow{2}{*}{$\begin{array}{l}\text { Types/subtypes of } \\
\text { flu viruses isolated }\end{array}$} & \multirow[t]{2}{*}{ Gender } & \multirow{2}{*}{$\begin{array}{l}\text { Age } \\
\text { (year) }\end{array}$} & \multicolumn{2}{|l|}{ Animal contacts } & \multirow[t]{2}{*}{ Travel history } \\
\hline & & & & & $\begin{array}{l}\text { Residential } \\
\text { neighboring areas }\end{array}$ & $\begin{array}{l}\text { Individual contacts } \\
\text { before onset }\end{array}$ & \\
\hline 108 & Taoyuan & $\mathrm{H} 3 \mathrm{~N} 2$ & $\mathrm{~F}$ & 25 & No & No & China/HK \\
\hline 515 & Yilan & $\mathrm{H} 3 \mathrm{~N} 2$ & M & 3 & No & Dog & No \\
\hline 517 & Yilan & $\mathrm{B}$ & M & 11 & No & Dog & ND \\
\hline 518 & Yilan & $\mathrm{H} 3 \mathrm{~N} 2$ & $\mathrm{~F}$ & 16 & No & No & No \\
\hline 618 & Kinmen & $\mathrm{H} 3 \mathrm{~N} 2$ & $\mathrm{~F}$ & 11 & Chicken & No & No \\
\hline 621 & Kinmen & $\mathrm{H} 3 \mathrm{~N} 2$ & $\mathrm{~F}$ & 13 & No & No & No \\
\hline 624 & Kinmen & H3N2 & M & 59 & No & No & No \\
\hline 704 & Tainan & $\mathrm{H} 3 \mathrm{~N} 2$ & M & 5 & Chicken & No & No \\
\hline 712 & Tainan & $\mathrm{H} 3 \mathrm{~N} 2$ & $\mathrm{~F}$ & 34 & Swine, pigeon and chicken & No & No \\
\hline
\end{tabular}

$\mathrm{F}=$ females, $\mathrm{M}=$ males, HK=Hong Kong. 
Table 2

Changes of several biologically important function sites/antigenic sites in HA1 gene of 10 Taiwan human flu isolates with H3N2 subtype

\begin{tabular}{lllllll}
\hline Virus & \multicolumn{2}{l}{ Changes in amino acid sites } & & & \\
\cline { 2 - 7 } & Ile144Asn & Gln156His & Ser186Gly & Gly225Asp & 227 & Gly275Asp \\
\hline A/Taiwan-Taoyuan/108/03(H3N2) & $\mathrm{N}$ & $\mathrm{Q}$ & $\mathrm{G}$ & $\mathrm{D}$ & $\mathrm{S}$ & $\mathrm{G}$ \\
A/Taiwan-Yilan/513/03(H3N2) & $\mathrm{N}$ & $\mathrm{H}$ & $\mathrm{G}$ & $\mathrm{D}$ & $\mathrm{S}$ & $\mathrm{G}$ \\
A/Taiwan-Yilan/518/03(H3N2) & $\mathrm{N}$ & $\mathrm{H}$ & $\mathrm{G}$ & $\mathrm{D}$ & $\mathrm{S}$ & $\mathrm{G}$ \\
A/Taiwan-Tainan/704/03(H3N2) & $\mathrm{N}$ & $\mathrm{H}$ & $\mathrm{G}$ & $\mathrm{D}$ & $\mathrm{S}$ & $\mathrm{G}$ \\
A/Taiwan-Tainan/712/03(H3N2) & $\mathrm{N}$ & $\mathrm{H}$ & $\mathrm{G}$ & $\mathrm{D}$ & $\mathrm{S}$ & $\mathrm{G}$ \\
A/Taiwan-Kinmen/624/03(H3N2) & $\mathrm{N}$ & $\mathrm{H}$ & $\mathrm{G}$ & $\mathrm{D}$ & $\mathrm{S}$ & $\mathrm{G}$ \\
A/Taiwan-Kinmen/618/03(H3N2) & $\mathrm{N}$ & $\mathrm{Q}$ & $\mathrm{G}$ & $\mathrm{D}$ & $\mathrm{P}$ & $\mathrm{D}$ \\
A/Taiwan-Kinmen/621/03(H3N2) & $\mathrm{N}$ & $\mathrm{Q}$ & $\mathrm{G}$ & $\mathrm{D}$ & $\mathrm{P}$ & $\mathrm{D}$ \\
Function & $\mathrm{A}$ & $\mathrm{B}$ & $\mathrm{B}$ & $\mathrm{R}$ & $\mathrm{C}$ & $\mathrm{F}$ \\
\hline
\end{tabular}

A: antigenic site; B: near antibody-combining site; R: sialic acid receptor-binding site; C: difference between Taiwan and Kinmen; F: rapid rates of amino acid replacement.

A/Swine/PingTung-Taiwan/199.2/2002(H3N2), but they had 75-77\% homology with the HA1 [414-924 (511 bp)] gene segments of A/Wild Bird/Taiwan/243/2002 and A/Mallard Duck/Taiwan/3.3/2003.

\subsection{Phylogenetic analysis}

To investigate possible animal gene segments, the M, HA and NA genes of human H3N2 isolates in 2002-2003 were compared and found to be all of "human origin." Furthermore, all HA1 fragments of the human H3N2 viruses belong to the lineage of A/ Fujian/411/2002(H3N2) and A/Ningbo/17/2002(H3N2) in Zhejiang province in mainland China (data not shown). None of the HA, NA and M segments of A/Wild Bird/Taiwan/ 243/02-like nor A/Mallard Duck/Taiwan/3.3/03-like and A/swine/PingTung-Taiwan/ 199.2/02-like isolates were detected in these human influenza viruses.

\section{Discussion}

Continuous antigenic drift of amino acid changes in the HA gene occurred in 2002 2003 influenza A isolates obtained from both the main Taiwan island and Kinmen islet, indicating that different geographic areas revealed such changes differently (position 227 of HA gene: Pro in Kinmen vs. Ser in Taiwan). Up to now, all those human H3N2 isolates collected from animal epidemic areas, rural pig/avian farms and migrating bird habitats have still been found to be of "human origin" by phylogenetic analysis of M, HA and NA gene segments. The investigations of other internal genes are in progress.

Epidemiological findings demonstrated that travel history to China/Hong Kong made a great difference in changes of flu A viruses [8]. By contrast, residents who lived near the habitats of migrating birds or the surrounding rural areas, where many avian and swine farms are located, had little effect on acquiring flu A virus infection directly from swine or avian species. In summary, this is the first study to demonstrate the importance of human virological surveillance in high-risk areas, including travelers and animal contacts in Taiwan. Such a study will be very valuable in those countries/areas with many visitors coming from affected areas where novel influenza virus has emerged. 


\section{References}

[1] T.D. Szucs, Influenza. The role of burden-of-illness research, Pharmacoeconomics 16 (Suppl. 1) (1999) $27-32$.

[2] D.M. Fleming, The impact of three influenza epidemics on primary care in England and Wales, Pharmacoeconomics 9 (Suppl. 3) (1996) 38-45discussion 50-3.

[3] R.G. Webster, Influenza: an emerging disease, Emerg. Infect. Dis. 4 (3) (1998) 436-441.

[4] R.G. Webster, A molecular whodunit, Science 293 (2001) 1773-1774.

[5] A. Abbott, Human fatality adds fresh impetus to fight against bird flu, Nature 423 (6935) (2003) 5.

[6] J. Clayton, Looming flu pandemic has experts crying fowl, Nat. Med. 9 (4) (2003) 375.

[7] Y. Guan, et al., Emergence of multiple genotypes of H5N1 avian influenza viruses in Hong Kong SAR, Proc. Natl. Acad. Sci. U. S. A. 99 (13) (2002) 8950-8955.

[8] R.F. Grais, J.H. Ellis, G.E. Glass, Assessing the impact of airline travel on the geographic spread of pandemic influenza, Eur. J. Epidemiol. 18 (11) (2003) 1065-1072. 